\title{
Effect on Compressive Strength of Concrete Using Treated Waste Water for Mixing and Curing of Concrete
}

\author{
HUMMAIRA KANWAL* ${ }^{*}$, SABAHAT ARIF**, MUHAMMAD AFZAL JAVED*, AMIR FAROOQ*, AND \\ MUHAMMAD ARIF KHAN***
}

RECEIVED ON 18.08.2017 ACCEPTED ON 13.11.2017

\begin{abstract}
Effective utilization of the available resources is imperative approach to achieve the apex of productivity. The modern world is focusing on the conditioning, sustainability and recycling of the assets by imparting innovative techniques and methodologies. Keeping this in view, an experimental study was conducted to evaluate the strength of concrete made with treated waste water for structural use. In this study ninetysix cylinders of four mixes with coarse aggregates in combination with FW (Fresh Water), WW (Wastewater), TWW (Treated Wastewater) and TS (Treated Sewage)were prepared. The workability of fresh concrete was checked before pouring of cylinders. The test cylinders were left for 7, 14, 21 and 28 days for curing. After curing, the compressive strength was measured on hardened concrete cylinders accordingly. Test results showed that workability of all the four mixes were between $25-50 \mathrm{~mm}$ but ultimate compressive strength of concrete with WW was decreased and with TWW, TS at the age of 28 days do not change significantly. This research will open a new wicket in the horizon of recycling of construction materials. The conditioning and cyclic utilization will reduce the cost of the construction and building materials as well as minimize the use of natural resources. This novelty and calculating approach will save our natural assets and resources.
\end{abstract}

Key Words: Recycled Aggregate, Fresh Water, Wastewater, Treated Wastewater, Treated Sewage, Concrete, Compressive Strength.

\section{INTRODUCTION}

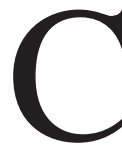

ement concrete is a major building material used abundantly in the construction industry. It is used in all parts of the building like foundations, superstructures and roofs. Water is required for the preparation (mixing) of concrete as it not only to make the concrete place able but also impart strength to the concrete by the process of cement hydration [1].
Concrete structures have deteriorated with time due to presence of minerals in the water used for their construction or due to the presence of sulphates in the ground water [2]. Edible water is considered fit to be used for mixing, placing and hydration of concrete. Fresh (edible) water is usually obtained from underground and

$\dagger$ Corresponding Author (E-Mail: hmughal84@gmail.com)

Department of Technology, The University of Lahore, Lahore.

** Department of Product and Industrial Design, University of Engineering \& Technology, Lahore.

*** Department of Architectural Engineering \& Design, University of Engineering \& Technology, Lahore.

This is an open access article published by Mehran University Research Journal of Engineering and Technology, Jamshoro under the CC by 4.0 International License. 
surface resources. FW is diminishing and water table being lowered day by day due to its excessive use. This is creating negative impact on the environment. Therefore, alternative resources have to be explored [3]. To preserve the natural FW resources an alternate way is to use recycled WW for construction purposes which has no adverse effect on concrete. However, some harmful impurities like silt, clay and sand, need to be removed by sedimentation $[1,4]$ etc.

About $80 \%$ of the water supplied for the residential purposes comes out as WW [1,3]. This WW contains some impurities and solid particles, which may affect some of concrete properties like setting time, hardening, density, workability and strength. The presence of chlorides, sulphates and soluble bases may be harmful for the strength and durability of the concrete. However, WW after treatment can be used for concrete as mixing and curing of concrete. Therefore, presence of chlorides, sulfates, soluble bases, solids in the WW should properly be addressed [5].

In our country various water sources are available in different regions and going lowered day by day[3,6]. The main objective of this study is to explore the possibility to use WW in the mixing and curing of concrete after treatment. The degree (primary or secondary) of the water treatment to obtain required useable water is also explored.

\section{MATERIALS AND METHOD}

- $\quad$ OPC (Ordinary Portland Cement) DG 53 is used for the preparation of concrete. It is obtained from a single vender for the whole experimentation.

- Locally available sand is used to make concrete in all mixings.

- $\quad$ In this study margalla crush has been used for making of the concretes. It is sieved to obtain the required size of the aggregate (20 $\mathrm{mm}$ down).
The maximum size of coarse aggregate is less than $20 \mathrm{~mm}$ to get the maximum increase in compressive strength. A sieve analysis (ASTM C 116-04, C 117-05) are carried out on coarse aggregate to obtain the required size (20 and 12mm) [7-8].

In this study, the WW is collected from Lahore canal (Thokar) and plain treatment is done by sedimentation [8]. However, the TS is collected from Chokera Treatment Plant situated in Faisalabad. While portable water is obtained from FW supply in The University of Lahore.

WW is tested in laboratory to find out its chemical properties like pH, Turbidity, Chlorides, Sulphates, Conductivity and TSS (Total Suspended Solids) [9-10]. This water is treated using primary treatment (sedimentation) method to make this water fit for concreting i.e. as good as FW. In this way FW can be saved by using treated WW in construction industry.

\subsection{Mix Design}

The concrete with a nominal strength of 21MPa (3000 Psi) was prepared using a nominal mix of 1:2:4. The w/c ratio was kept to 0.6 similar to the one used in the previous studies [11,12].

\section{$2.2 \quad$ Mixing}

Four types of mix M1, M2, M3 and M4 with different water quality have been used in this research.

- $\quad$ M1:100\% FW and Margalla crush.

- $\quad$ M2:100\% WW and Margalla crush.

- $\quad$ M3:100\% TWW and Margalla crush.

- $\quad$ M4:100\% TS and Margalla crush.

\section{$2.3 \quad$ Workability}

Workability of M1, M2, M3 and M4 mix were measured using the slump test (ASTM C 143). 


\section{$2.4 \quad$ Casting}

Casting is done after measuring the workability of concrete. Ninety-six cylinders in total (24 cylinders for each type of water) were casted in accordance with the (ASTM C-192), to test the cylinders at different ages. The detail of the cylinders is given in Table 1.

\subsection{Curing}

Curing is done by immersing the cylinders in curing water for specified days. Normal fresh (tap) water, WW, TWW and TS were used for the curing purpose separately. For four mixes, four curing ages were selected i.e. 7, 14, 21 and 28 days.

\section{EXPERIMENTAL WORK}

Different properties of the water and concrete have been measured through the standard experiments.

\subsection{Water Quality}

Three types of water were selected in order to get a wide range of chemical composition of water (Table 1) and measuring of $\mathrm{pH}$ and Turbidity in Figs. 1-2. Waste water has been collected from BRB (Bambawali Ravi Bedian) canal and its chemical properties are analyzed in the Environmental laboratory of The University of Lahore. Laboratory results are revealed which are shown in Table 2. Table 2, all parameters are addressed within a suitable range like $\mathrm{pH}$, Turbidity, presence of Chlorides, Sulphates, Conductivity and TSS.

\subsection{Measuring of $\mathrm{pH}$}

$\mathrm{pH}$ meter is used to measure the $\mathrm{pH}$ of all types of water which is shown in Fig. 1. If $\mathrm{pH}$ is 7 then water is neutral in nature, if greater than 7 then water is basic, if less than 7 then water is acidic in nature.

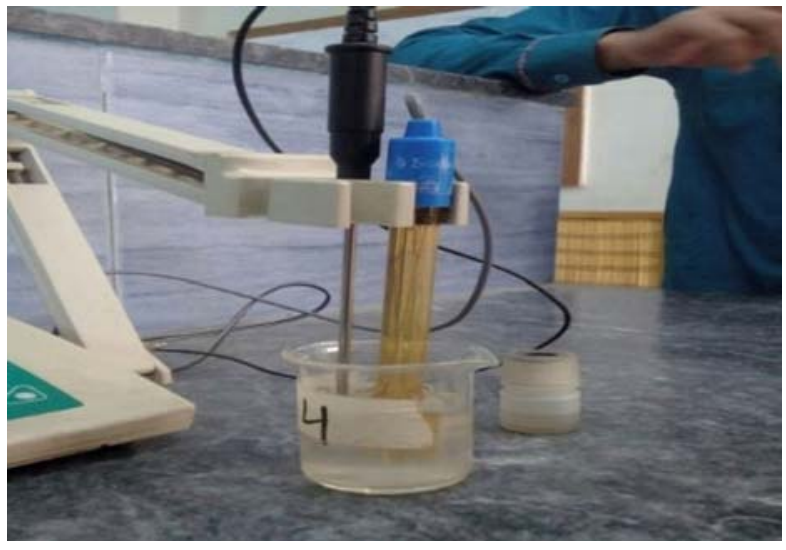

FIG. 1. MEASURING PH OF WASTEWATER (UOL LAB)

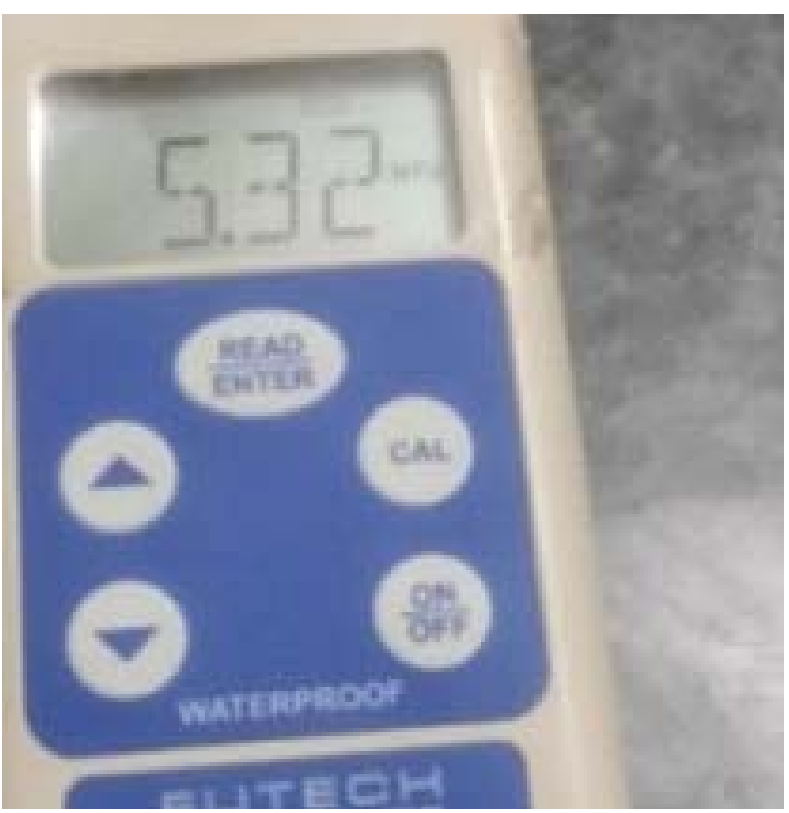

FIG. 2. TURBIDITY METER (UOL LAB)

TABLE 1. NUMBER OF CYLINDERS CASTED

\begin{tabular}{|c|c|c|c|c|c|}
\hline Description & Days & FW & WW & TWW & TS \\
\hline \multirow{3}{*}{96 Cylinders } & 7 & & & & \\
\cline { 2 - 5 } & 14 & 6 & 6 & 6 \\
\cline { 2 - 5 } & 21 & & & & \\
\hline
\end{tabular}

Mehran University Research Journal of Engineering \& Technology, Volume 37, No. 2, April, 2018 [p-ISSN: 0254-7821, e-ISSN: 2413-7219] 


\subsection{Measuring of Turbidity}

Turbidity meter is used to measure the turbidity of water which is shown Fig. 2. Turbidity is the concentration of solids and minerals which is present in water.

\subsection{Workability of Concrete}

Workability is the ease of placing and compacting the concrete in different parts of a structure. The usual range of workability is taken as $25-50 \mathrm{~mm}$ for use in foundations, slabs, beams and columns etc. Workability has been measured using ASTM C 143.and shown in Fig. 3.

\subsection{Compressive Strength of Concrete}

Concrete cylinders were tested at room temperature according to the ASTM C 39. Cylinders were taken out of curing tank after the respective days, wiped off and kept at room temperature for 2 hours. Then cylinders were caped which is shown in Fig. 4. Caped cylinders were placed in the compression testing machine which is shown in Figs. 5-6. Load was applied at a constant rate up to the ultimate (crushing) strength. Similarly, all the cylinders were tested at the corresponding ages.

\section{RESULTS AND DISCUSSION}

\subsection{WORKABILITY}

The results of the slum tests performed on the four types of the mixes are presented in Table 3. The Results show

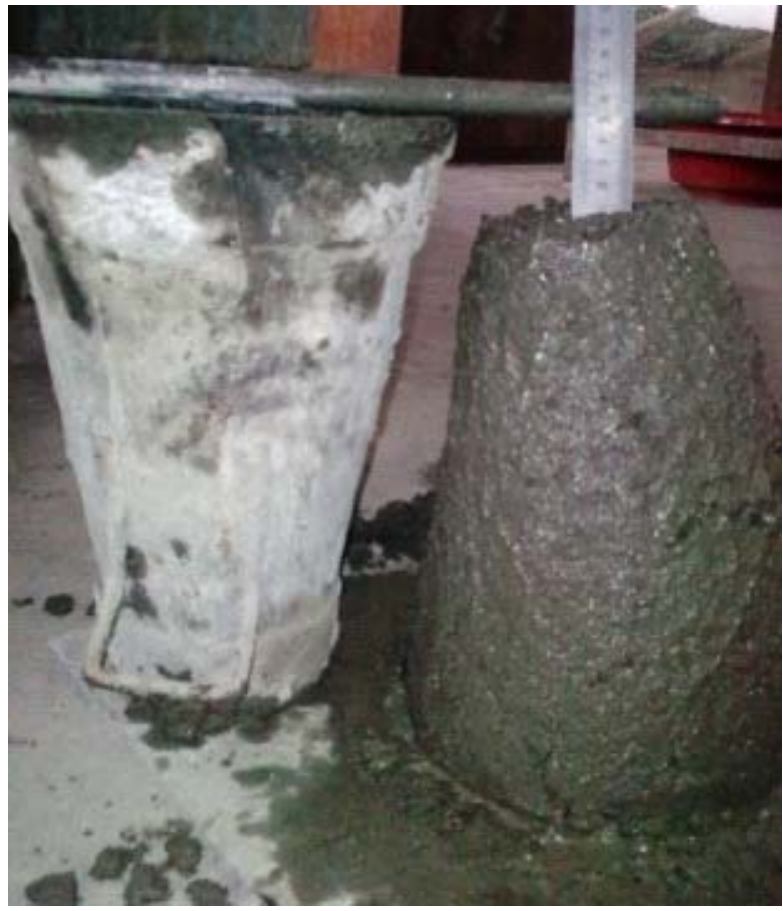

FIG. 3. MEASURING THE WORKABILITY OF CONCRETE (UOL LAB)

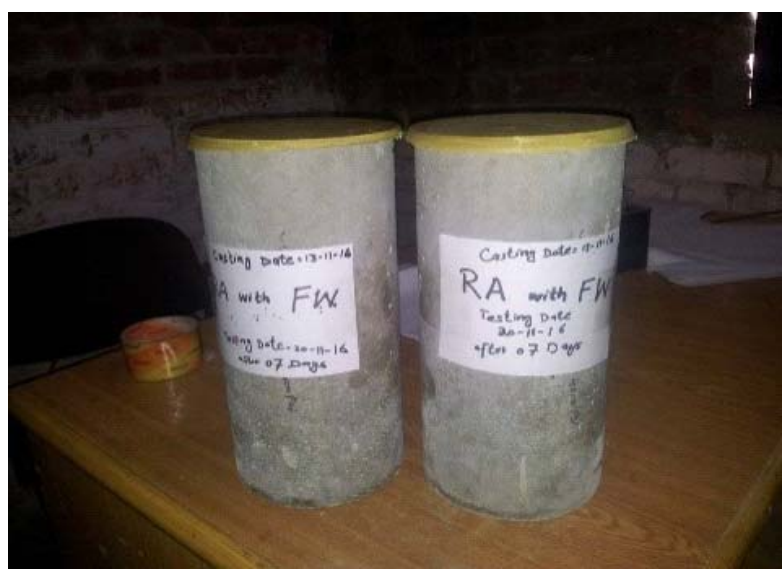

FIG. 4. CONCRETE CYLINDERS READY FOR TESTING (UOL $L A B)$

TABLE 2. LABORATORY TESTS OF WATER SPECIMENS

\begin{tabular}{|c|c|c|c|c|c|c|c|}
\hline No. & Parameters & FW & WW & TWW & TS & WHO & Pakistan Guidelines \\
\hline 1. & Temperature $\left({ }^{\circ} \mathrm{C}\right)$ & $20-25$ & $18-22$ & $18-20$ & 20.3 & $8-20^{\circ} \mathrm{C}$ & $8-20^{\circ} \mathrm{C}$ \\
\hline 2. & $\mathrm{Ph}$ & 7.04 & 7.4 & 7.8 & 7.1 & $6.5-8.5$ & $6.5-8.5$ \\
\hline 3. & Turbidity (NTU) & Nil & 77 & 4.7 & 53 & $<5$ & $<5$ \\
\hline 4. & Chlorides (ppm) & 115 & 182 & 160 & 73 & $<250$ & $<250$ \\
\hline 6. & Conductivity ( $\mu s)$ & 185 & 294 & 174 & 139 & $<1000$ & $<1000$ \\
\hline 7. & Total Solids (ppm) & 660 & 707 & 885 & 356 & $<1000$ & $<1000$ \\
\hline
\end{tabular}

Mehran University Research Journal of Engineering \& Technology, Volume 37, No. 2, April, 2018 [p-ISSN: 0254-7821, e-ISSN: 2413-7219] 
that workability of the mixes is within the acceptable range for the 1:2:4 concrete. The normal range for the workability for this mix is from 25-50mm which is shown in Fig 7. Workability of fresh concrete is maximum for the mix formed and cured with fresh water. Workability decreases slightly when prepared with TS (from plant). However, the workability of mix formed and cured with wastewater is lowest.

Workability of concrete for M1, M2, M3 and M4 mixes is shown in Fig. 7 which is between 25-50mm.

\subsection{Compressive Strength}

Compressive strengths are calculated by taking average of six tested samples for each type of mix at different ages.M1, M2, M3 and M4 have been plotted in Fig 8-12.

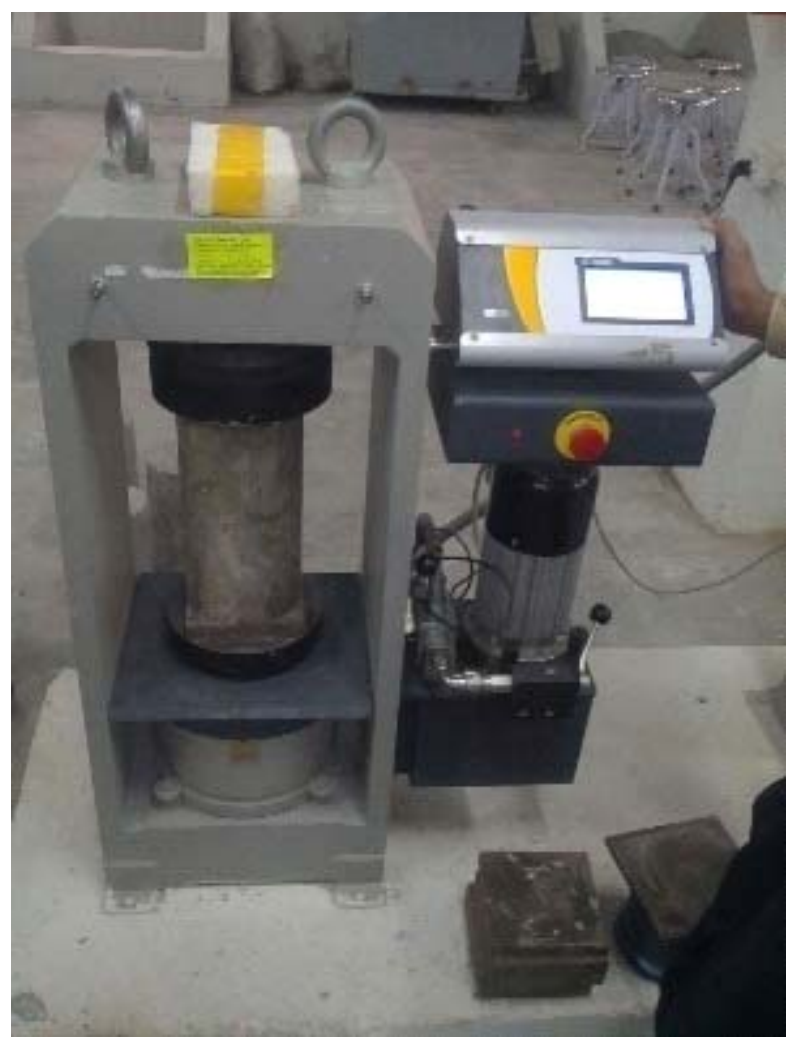

FIG. 5. COMPRESSION TESTING MACHINE (UOL LAB)

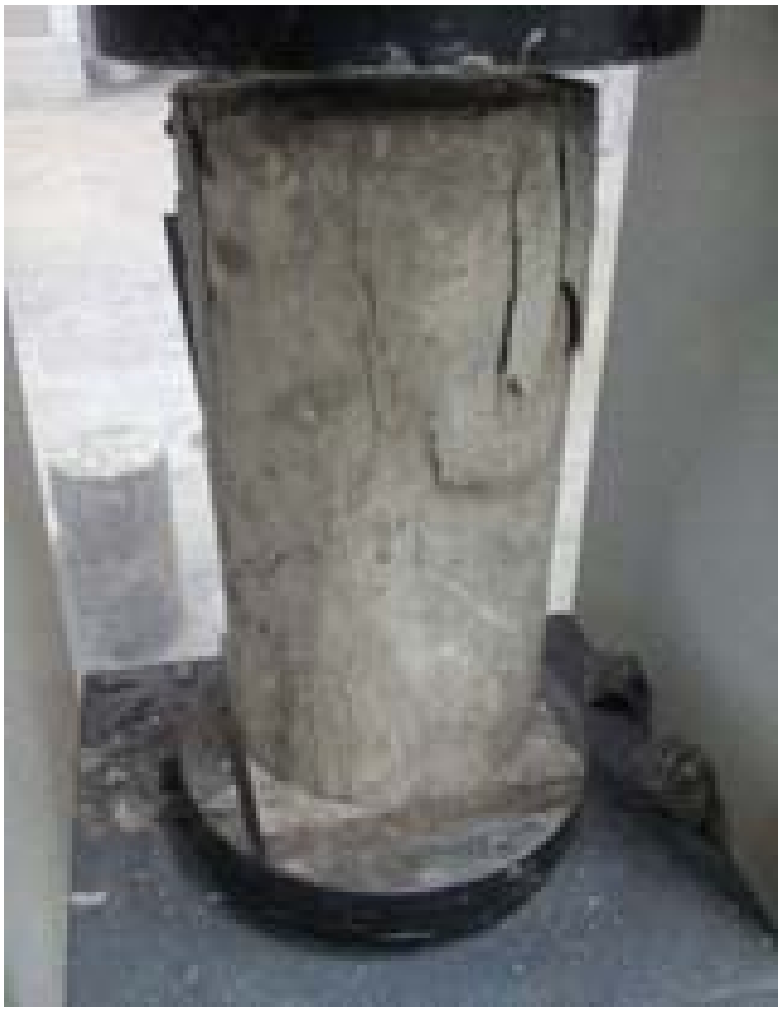

FIG. 6. CRUSHING FAILURE (UOL LAB)

TABLE 3. SLUMP TEST RESULTS

\begin{tabular}{|c|c|c|}
\hline No. & Description & Shmp Vahe (mm) \\
\hline 1. & RA + FW & 50 \\
\hline 2. & RA + WW & 35 \\
\hline 3. & RA + TWW & 42 \\
\hline 4. & RA + TS & 48 \\
\hline
\end{tabular}

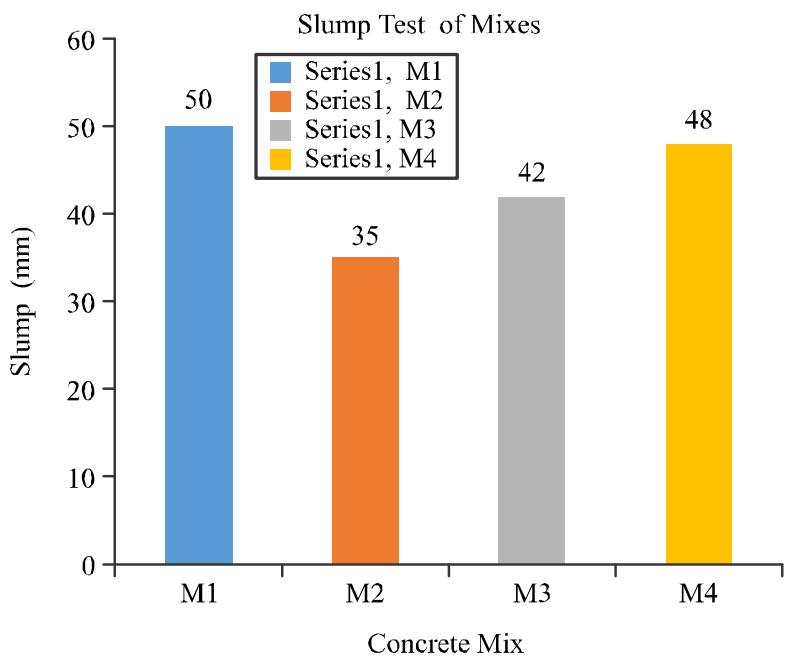

FIG. 7. SLUMP OF M1, M2, M3 AND M4 


\subsubsection{Mix M1 (Fresh Water)}

Compressive strength of concrete is measured by testing cylinder at respective days. The compressive strength varies with age, i.e. maximum at 28 days and minimum at the age of 7 days shown in Fig. 8. The strength varies from 11-20.35 MPa. However, the designed strength of this mix is $21 \mathrm{MPa}$ (at 28 days).

\subsubsection{Mix M2 (Wastewater)}

This mix is made using waste water. The strength varies between 11.72MPa and 18.2MPa shown in Fig. 9. It shows that 7 days strength is same as of M1 but 28 days strength is less than that of M1. This may be due the presence of suspended waste particles or other impurities. However, strength of mix M2 is slightly less than that of mix M1.

\subsubsection{Mix M3(Treated Wastewater)}

Compressive strength of the Mix M3 ranges from 12.82 MPa at 7 days and 20.09 MPa at 28 days shown in Fig. 10 which is slightly better than that of Mix M2. It shows that the treated waste water is good for use to mix and cure the concrete. Its strength is very near to the mix M1.

\subsubsection{Mix M4 (Treated Sewage)}

Compressive strength of the Mix M4 ranges from 13.73 MPa at 7 days and 21.2 MPa at 28 days shown in Fig. 11 which is slightly better than that of Mix M1 and Mix M3.

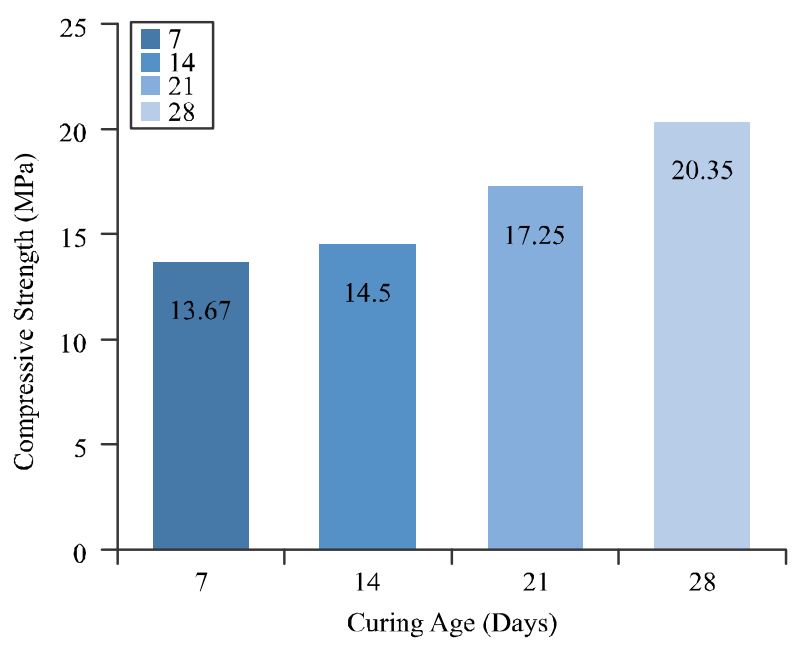

FIG. 8. COMPRESSIVE STRENGTH OF M1
It shows that the treated sewage is good for use to mix and cure the concrete. Its strength is very near to the mix M1.

\subsection{Comparison of Compressive Strength at Different Ages}

The summary of mix M1,mix M2,mix M3 and mix M4 are shown in Fig. 12 at the age of 7,14 21 and 28 days.

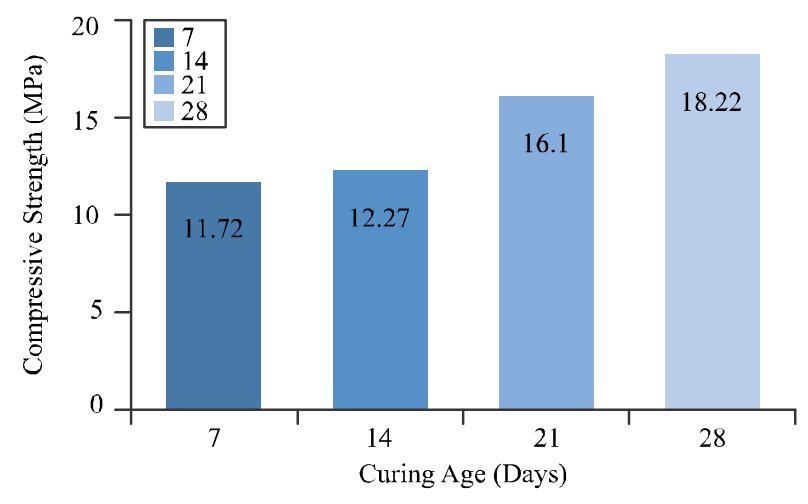

FIG. 9. COMPRESSIVE STRENGTH OF M2

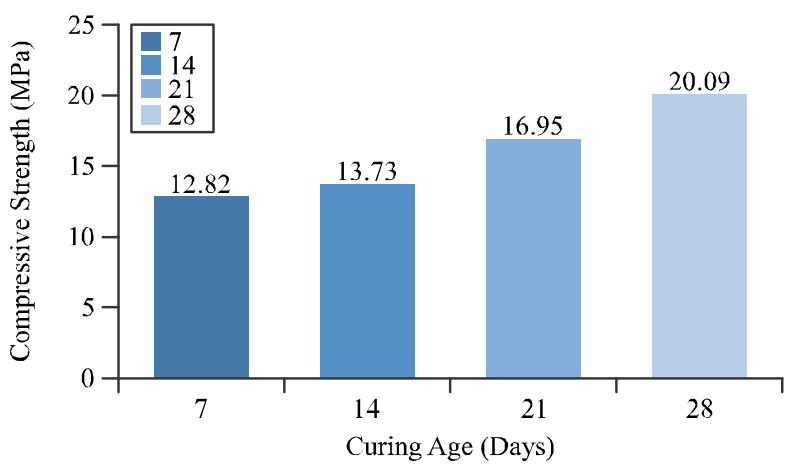

FIG. 10. COMPRESSIVE STRENGTH OF M3

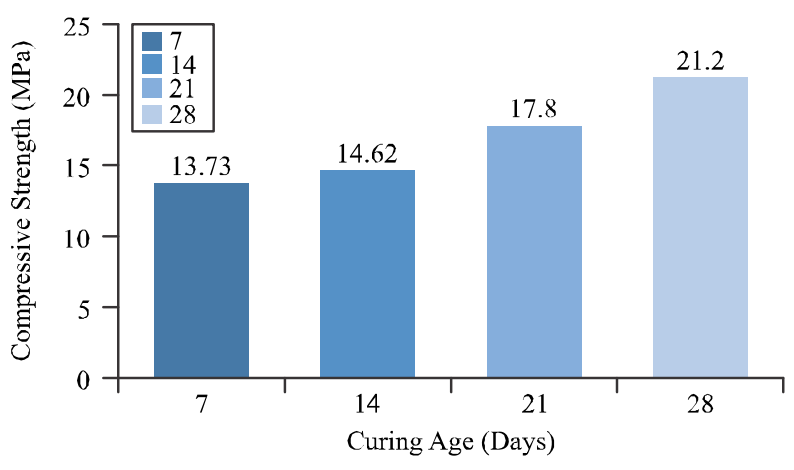

FIG. 11. COMPRESSIVE STRENGTH OF M4 


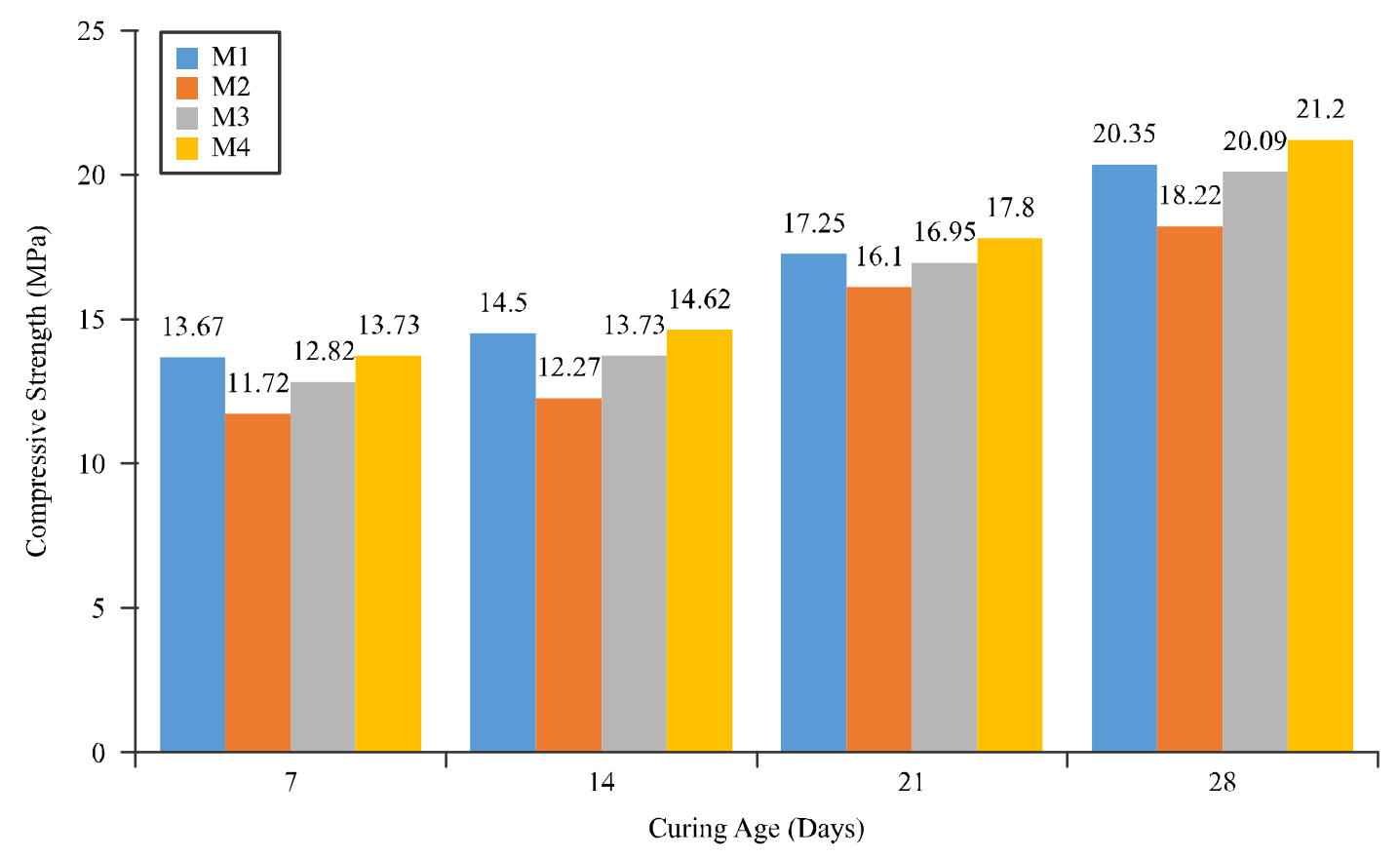

FIG. 12. COMPARISON OF COMPRESSIVE STRENGTH AT DIFFERENT AGES OF ALL MIXES

\section{CONCLUSION}

The following conclusions have been drawn from the experimental results.

(i) Workability of the concrete made with FW of mix M1, WW of mix M2, TWW of mix M3 and TS of mix M4 lies between 25-50mm, which is adequate for normal use of concrete. The workability of concrete with FW is highest and for concrete with WW is lowest.

(ii) Compressive strength (fc') of all the mixes increased with age. The strength of concrete (M1) made from FW is higher than concrete (M2) made from WW and concrete M3 made by using (TWW). The strength of concrete (M4) made from TS is however slightly more than the control mix i.e. M1. It shows that treatment of the sewage produced water can be used instead of tap water. (iii) As the strength of concrete M1 and M4 are almost same. Therefore, the treated WW can be used for mixing and curing of concrete without any loss of strength.

(iv) As the strength of M4 is highest so water treated by the proper treatment plant, should be used for mixing and curing of concrete.

\section{ACKNOWLEDGEMENT}

The authors gratefully acknowledge the assistance provided by the University of Engineering \& Technology, Lahore, and facilitation from The University of Lahore, Pakistan. Authors also thankful to the staff of Environmental and Concrete Lab staff of The University of Lahore who provide me assistance to complete my research.

\section{REFERENCES}


[2] Vinut, K., and Suresh, G.P., "A Study on Compressive Strength of Concrete by Using Treated Domestic Waste Water”, International Journal of Research in Engineering and Technology, Volume 2, [ISSN: 2321-0613], India, 2014.

Shrilatha, M.R., H.C.P., and Naveen, K.K., "Effect of Primary Treated Waste Water n Concrete Mix”, Department of Civil Engineering, SJB Institute of Technology, Volume 4, Karnataka India, 2017.

Kazi, P.F., Al-Tamimi, A.K., Hamweyah, W., and Iqbal, F., "Evaluation of Sustainable Concrete Produced with Desalinated Reject Brine”, International Journal of Sustainable Built Environment, Volume 6, pp. 183-190, 2017.

Ansari, U.S., "Effect of Treated Waste Water on Strength of Concrete”, Shri Guru Gbbind Singhji Institute of Engineering \& Technology, 2016.
Ferria, L., Brito, J., and Barra, M., "Influence of the Pre-Saturation of Recycled Coarse Aggregates on Concrete Properties”, Magazine of Concrete Research, 2015.

[8] Katib, A.W., "Design and Performance of Sustainable/ Green Concrete", M.Sc. Thesis, American University of Sharjah, Sharjah, UAE, 2015.

[9] Olugbenga, A.T.A., "Effect of Different Sources of Water on Concrete Strength: A Case Study of Ile-Ife”, Department of Building, 2014.

[10] Ghodake, R.B., Nimbalkar, H.N., Chandake, P.P., Narute, D.Y., Maniyar, S.P., and More, A.B., "Reuse of Treated Domestic Waste Water in Concrete - A Sustainable Approach”, Indian Journal of Applied Research, Volume 4, [ISSN: 2249-555X], 2014.

[11] Bhagat, D.K., Parmer, J.P., Tank, Y.R., and Gadhiya, D.H., "Experimental Study of Compressive Strength of Recycled Aggregate Concrete”, International Journal of Engineering Research\& Technology, Volume 3, No. 4, 2014.

[12] Alenezi, N., "Evaluation and Assessment of Concrete Produced by Utilizing of Treated Waste Water", Concrete Sustainability Conference, Kuwait Institute of Scientific Research, 2010. 